54996 eligible individuals, 52029 (95\%) responded. In 2006, we delivered another questionnaire to all community-dwelling individuals aged over 40 years in Ohsaki City. Of 77325 eligible individuals, $49603(64.2 \%)$ responded. The 9206 participants who answered both questionnaires were classified by self-reported sleep duration: $\leq 5 \mathrm{~h}$ (short sleep), $6 \mathrm{~h}, 7 \mathrm{~h}$ (reference), $8 \mathrm{~h}$, and $\geq 9 \mathrm{~h}$ (long sleep). The main outcome measure was a weight gain of $\geq 10 \mathrm{~kg}$ or a body mass index (BMI) of $\geq 25 \mathrm{~kg} / \mathrm{m}^{2}$ (obesity) calculated from selfreported height and weight. We used logistic regression analyses to derive ORs and 95\% CIs adjusted for sex, age, BMI, education, smoking, alcohol drinking, occupation, marital status, menopausal status, and caffeine beverage consumption.

Results We observed no association between sleep duration and risk of weight gain and obesity. Multivariate ORs for weight gain were 1.14 (95\% CI 0.70 to 1.87) for short sleep and 1.16 (95\% CI 0.90 to 1.51 ) for long sleep. Multivariate ORs for obesity were 0.98 (95\% CI 0.62 to 1.55) for short sleep and 1.05 (95\% CI 0.83 to 1.33) for long sleep.

Conclusion Sleep duration does not affect the risk of weight gain or obesity.

\section{P2-456 EVALUATING BURDEN OF ROTAVIRUS-ASSOCIATED MORTALITY IN THE EASTERN MEDITERRANEAN REGION; A CRUCIAL STEP FOR INFORMED DECISION-MAKING ON IMPLEMENTATION OF ROTAVIRUS VACCINE}

doi:10.1136/jech.2011.142976l.84

M Naghipour, ${ }^{*}$ T B Taleshi. Guilan University of Medical Sciences, Rasht, Iran

Introduction Rotavirus-attributed diarrhoea is a major cause of death in young children. The WHO-Eastern Mediterranean Region, with a population over 590 millions, is a diverse area in terms of socioeconomic status and health indicators. This study aimed to evaluate the burden of rotavirus-associated mortality in order to encourage implementation of rotavirus vaccine.

Methods Based on rotavirus-associated mortality in the pre-vaccination period, the effect of rotavirus vaccine to avert children deaths was calculated.

Results In the Eastern Mediterranean Region more than 61000 children aged $<5$ years died of rotavirus in 2004. Pakistan and Afghanistan, each with more than 15000 deaths per year, were the countries with the highest rates of rotavirus-associated mortality; follow by Iraq, Somalia, Sudan, Yemen, Egypt and Morocco. Bahrain, Kuwait and Qatar with less than 10 deaths per year were the countries with the lowest rates of rotavirus-associated mortality. When the coverage of currently used vaccines was applied to a rotavirus vaccine, a minimum of 24100 and maximum of 43300 deaths would be averted with vaccine efficacy of $50 \%$ to $90 \%$, respectively.

Conclusion Rotavirus-associated mortality and morbidity varies considerably in the region. While in some countries reducing rotavirus-associated mortality is a great concern, in others reducing rotavirus-attributed morbidity is the main benefit of rotavirus immunisation. Implementing comprehensive strategies to facilitate usage of rotavirus vaccine in the region is encouraged.

\section{P2-457 TRADE IS ASSOCIATED WITH THE DISTRIBUTION OF UNDER, OVER, AND NORMAL WEIGHT AMONG ADULT RESIDENTS OF LOW-AND-MIDDLE-INCOME COUNTRIES: A MULTILEVEL ANALYSIS USING DATA FROM THE WORLD HEALTH SURVEYS}

doi:10.1136/jech.2011.142976l.85

A Nandi.. McGill University, Montreal, Quebec, Canada

Introduction Few empirical studies have investigated the relation between trade and individual weight status.
Methods We used data from a sample of 81449 adults from 24 lowand-middle-income countries who took part in the World Health Survey, a population-based survey of adults in 2002-2003, to examine the multilevel association between trade [ie, levels of trade, imports, and foreign direct investment (FDI)] and individual-level weight status.

Results The prevalence of underweight ranged from $2.51 \%$ $(\mathrm{SE}=0.85)$ in Bosnia-Herzegovina to $34.03 \%(\mathrm{SE}=1.05)$ in India and the prevalence of overweight ranged from $7.74 \%(\mathrm{SE}=0.69)$ in India to $49.08 \%$ ( $\mathrm{SE}=1.98$ ) in Russia. Marital, economic, and health status were among the most important individual-level predictors of weight. At the macro-level, FDI as a percent of GDP was associated with lower odds of underweight relative to normal weight for rural and urban residents, independently of individual-level covariates and country-level GDP and urbanisation. However, among rural men and women, FDI was positively associated with overweight compared to normal weight; a one unit increase in net inflow of FDI as a percent of GDP was associated with a 15\% higher odds of overweight relative to normal weight among rural men $(\mathrm{OR}=1.15,95 \% \mathrm{CI} 1.05$ to 1.26$)$ and women $(\mathrm{OR}=1.15,95 \%$ CI 1.07 to 1.23$)$

Conclusion Trade may be associated with individual weight status.

\section{P2-458 A DESCRIPTIVE STUDY ON THE TUBERCULOSIS IN MONGOLIA}

doi:10.1136/jech.2011.142976l.86

0 Nandinerdene, ${ }^{*}$ D Davaalkham. Department of Epidemiology and Biostatistics, Health Sciences University of Mongolia, Ulaanbaatar, Mongolia

Introduction Tuberculosis (TB) is highly prevalent in Mongolia, where approximately 4000 TB cases reported each year. The goal of this study is to determine the incidence of tuberculosis particularly MDR-TB cases registered in Mongolia.

Methods A descriptive method was used to study the incidence of MDR-TB reported in Mongolia. The information including age, gender, date of diagnosis, type of drug resistance, treatment outcomes were taken from national report.

Results Since the first diagnosis of MDR-TB in Mongolia, a total of 419 MDR-TB cases or 1.6 per cases per 10000 population were registered to date, which indicates the increasing tendency in the recent years. Average age $( \pm S D)$ of 419 MDR-TB cases was $32.3 \pm 10.9$, and $245(58.5 \%)$ were males. The highest MDR-TB morbidity reported in Selenge, Darhan-Uul, Dornod provinces. More than $60 \%$ of all MDR-TB cases were reported in Ulaanbaatar city. One hundred seventy nine $(42.7 \%)$ patients out of all confirmed MDR-TB cases are enrolled in treatment, 133 (31.7\%) are died prior to start treatment, $5(1.2 \%)$ are treated in non NTP units, $3(0.7 \%)$ are refused to receive MDR-TB treatment, 99 (23.6\% patients are in waiting list. The deaths are highly reported (61.8\%) since 2003 while the management of MDR-TB cases was in beginning stage and Second-line drugs was not procured.

Conclusion Incidences of tuberculosis as well as MDR-TB have been increasing during the last years in Mongolia so that early diagnosis and proper management is urgently required in this regard.

\section{P2-459 RESILIENCE AND RISK-TAKING BEHAVIOUR AMONG THAI ADOLESCENTS}

doi:10.1136/jech.2011.142976l.87

${ }^{1} \mathrm{P}$ Nintachan, ${ }^{*} \mathrm{~S}$ Vanaleesin, ${ }^{3} \mathrm{~L}$ Sanseeha, ${ }^{4} \mathrm{~K}$ Thummathai, ${ }^{5} \mathrm{P}$ Orathai. ${ }^{1}$ Psychiatric and Mental Health Division, Department of Nursing, Faculty of Medicine, Ramathibodi Hospital, Mahidol University, Bangkok, Thailand; ${ }^{2}$ Prince of Songkla University, 